\title{
Production and Properties of Amorphous TiCuNi Powders by Mechanical Alloying and Spark Plasma Sintering
}

\author{
J. C. Kim*, E. H. Kang, Y. S. Kwon, J. S. Kim, and Si-Young Chang ${ }^{a}$ \\ School of Materials Science and Engineering, University of Ulsan, Ulsan, 680-749, Korea \\ ${ }^{a}$ Department of Materials Engineering, Korea Aerospace University, Goyang, 412-791, Korea
}

(Received January 15, 2010; Revised January 29, 2010; Accepted February 8, 2010)

\begin{abstract}
In present work, amorphous TiCuNi powders were fabricated by mechanical alloying process. Amorphization and crystallization behaviors of the TiCuNi powders during high-energy ball milling and subsequent microstructure changes were studied by X-ray diffraction and transmission electron microscope. TEM samples were prepared by the focused ion beam technique. The morphology of powders prepared with different milling times was observed by field-emission scanning electron microscope and optical microscope. The powders developed a fine, layered, homogeneous structure with milling times. The crystallization behavior showed that glass transition, $\mathrm{T}_{\mathrm{g}}$, onset crystallization, $\mathrm{T}_{\mathrm{x}}$, and super cooled liquid range $\Delta \mathrm{T}=\mathrm{T}_{\mathrm{x}}-\mathrm{T}_{\mathrm{g}}$ were 628,755 and $127 \mathrm{~K}$, respectively. The as-prepared amorphous TiCuNi powders were consolidated by spark plasma sintering process. Full densified TiCuNi samples were successfully produced by the spark plasma sintering process. Crystallization of the MA powders happened during sintering at $733 \mathrm{~K}$.
\end{abstract}

Keywords : Amorphous, Mechanical alloying, High energy milling, Spark plasma sintering (SPS), Focused ion beam (FIB) technique

\section{Introduction}

Metallic glasses or amorphous alloys exhibit no long range regularity in the arrangement of their atoms or molecules. Due to the structural properties, the amorphous alloy exhibits outstanding yield strength and hardness, large elastic limit, excellent wear and corrosion resistance etc $[1,2]$. However, the amorphous alloy still has some limitations because of their low ductility and toughness at room temperature due to the formation of unstable shear bands under unconstrained loading. The amorphous alloy could be produced into various kinds of forms of thin sheets, rods, ribbons and powders from their raw melting stocks. Among them, the amorphous powders have been fabricated by several techniques such as a mechanical alloying, a melt spinning and a gas atomiza- tion, etc [3,4]. The mechanical alloying (MA) technique has been widely studied for formation of the amorphous powders. Consolidation of the amorphous powders generally requires low sintering temperature and short sintering time to prevent crystallization. Spark plasma sintering process (SPS) is known to be effective for powder consolidation due to its characteristics such as fast sintering, fast heating up and low sintering temperature in comparison with other conventional sintering methods [5].

Ti-based amorphous alloys are promising materials due to their outstanding mechanical properties with high corrosion resistance. Tensile strength and compressive strength values of the $\mathrm{Ti}$ amorphous systems are usually two or three times higher than those of conventional alloys [6-9]. In this work, Ti$\mathrm{Cu}-\mathrm{Ni}$ systems were chosen to produce the high per-

*Corresponding Author : [Tel : +82-52-259-2231; E-mail : jckimpml@ulsan.ac.kr] 
formance amorphous alloys. First, their amorphous powders were synthesized by MA and were subsequently consolidated by SPS process to obtain bulk samples. Microstructure, thermal stability, crystallization behavior of the mechanically alloyed amorphous powders and the characteristic of the bulk sample were investigated. In order to analysis the microstructure, TEM samples were prepared by the focused ion beam (FIB) technique.

\section{Experimental Procedure}

Amorphous $\mathrm{Ti}-\mathrm{Cu}-\mathrm{Ni}$ alloy powders were produced by mechanical alloying (MA) and subsequently consolidated by spark plasma sintering (SPS). Firstly, elemental powders with high purity (in Table 1) were accurately weighed and mixed to be the compositions of studied systems as listed in Table 2 . Then, high energy AGO-2 planetary ball mill was used to synthesize the amorphous powders. Hardened steel balls of $4.75 \mathrm{~mm}$ in diameter and $200 \mathrm{~g}$ in weight were used. The powders and the hardened steel balls were loaded together into a stainless steel vials with the ball to powder weight ratio of 20:1. Milling jar were evacuated and filled with $5 \times 10^{3} \mathrm{~Pa}$ Ar gas to avoid oxidation during milling. MA was performed at a rotational velocity of $300 \mathrm{rpm}$ up to 35 hrs. During milling the steel vials were watercooled.

Table 1. Specifications of the commercial elemental powders used in this study

\begin{tabular}{ccrl}
\hline \hline Element & Particle size & Purity & \multicolumn{1}{c}{ Product } \\
\hline $\mathrm{Ti}$ & -45 mesh & $99.7 \%$ & Rare Metallic Co., Ltd. \\
$\mathrm{Cu}$ & $-100+325$ mesh & $99.9 \%$ & Alfa Aesar \\
$\mathrm{Ni}$ & -100 mesh & $99.99 \%$ & Aldrich Chem. Co, Inc. \\
\hline
\end{tabular}

Table 2. Specifications of the compositions used in this study

\begin{tabular}{cc}
\hline \hline Composition (wt.\%) & Milling time (hrs) \\
\hline $\mathrm{Ti}_{50} \mathrm{Cu}_{30} \mathrm{Ni}_{20}$ & $2,5,10,20,25,30$ and $35 \mathrm{hrs}$ \\
$\mathrm{Ti}_{50} \mathrm{Cu}_{25} \mathrm{Ni}_{25}$ & $2,5,10,20,25$ and $30 \mathrm{hrs}$ \\
\hline
\end{tabular}

X-ray diffraction analysis was carried out to identify the phase and structure of the samples (X-ray diffractometer, Rigaku D-Max B). Step size of $0.08^{\circ}$ was used with scan speed $1^{\circ}$ per min. The X-ray scans for the amorphous (crystalline) samples were performed in the $2 \theta$ range from $20^{\circ}-80^{\circ}$.

Morphology and microstructure of the amorphous powders and sintered samples were observed by an optical microscope (OM), a field emission scanning electron microscope (FE-SEM) and a high resolution-transmission electron microscope (HR-TEM). In order to making the HR-TEM samples, the as-milled powders were directly sectioned using the focused ion beam (FIB) milling technique $[10,11]$ as shown in Fig. 1 . The dual beam FIB instrument (FEI, Nova Nanolab 600) was used in this study using $30 \mathrm{keV} \mathrm{Ga}{ }^{+}$ions. This instrument allowed the specimen to be in-situ manipulated with a needle-probe and also incorporated a gas injection system for ion-beam-assisted chemical vapor deposition. The powder samples for FIB treatment were prepared by dusting a small portion onto double-stick carbon tape adhered to a specimen holder. Ion beam currents ranging from 1 to 7 nA were used for cross-sectioning the powder particles, while ion-milling of blanks to TEM specimens was conducted at currents between 10 and $500 \mathrm{pA}$.

Thermal analysis was carried out using a Netzch STA 409 Differential Scanning Calorimeter (DSC). The DSC system was used for the investigation of decomposition transformations involving metastable at temperature between room temperature and $850 \mathrm{~K}$. The glass transition temperature, crystallization temperature and enthalpy of samples were determined.

Sintering of the MA powders was performed by means of an SPS-515 apparatus (Sumitomo Coal Mining, Japan). An amount of several grams of the as-milled amorphous powders were loaded in a WC die (10 $\mathrm{mm}$ diameter) and punch unit with a pressure of $500 \mathrm{MPa}$. Sintering temperature was mea- 


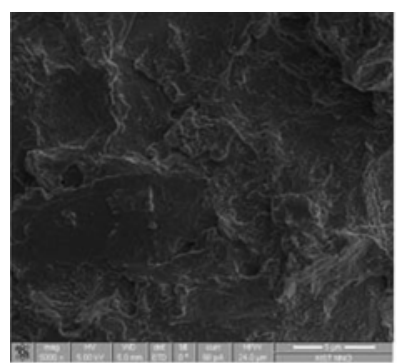

Powder

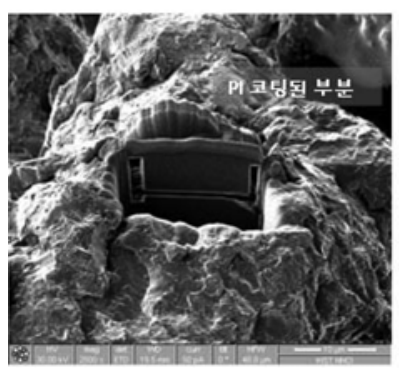

TEM samples by ion beam

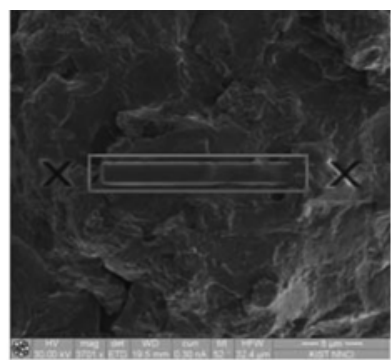

Pt coating

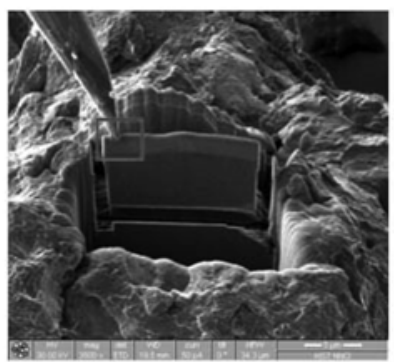

Tip attachment

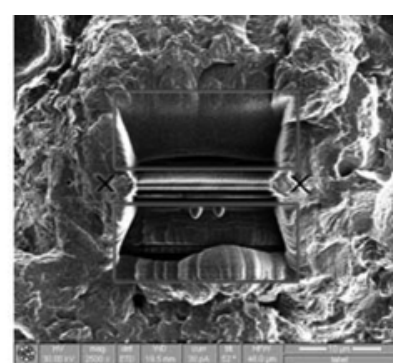

Cutting by ion beam

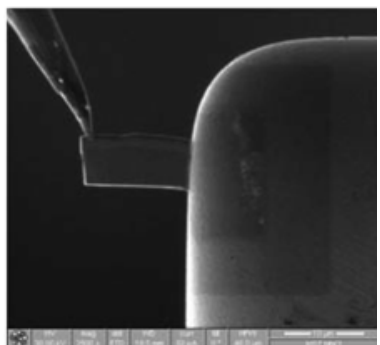

TEM grid
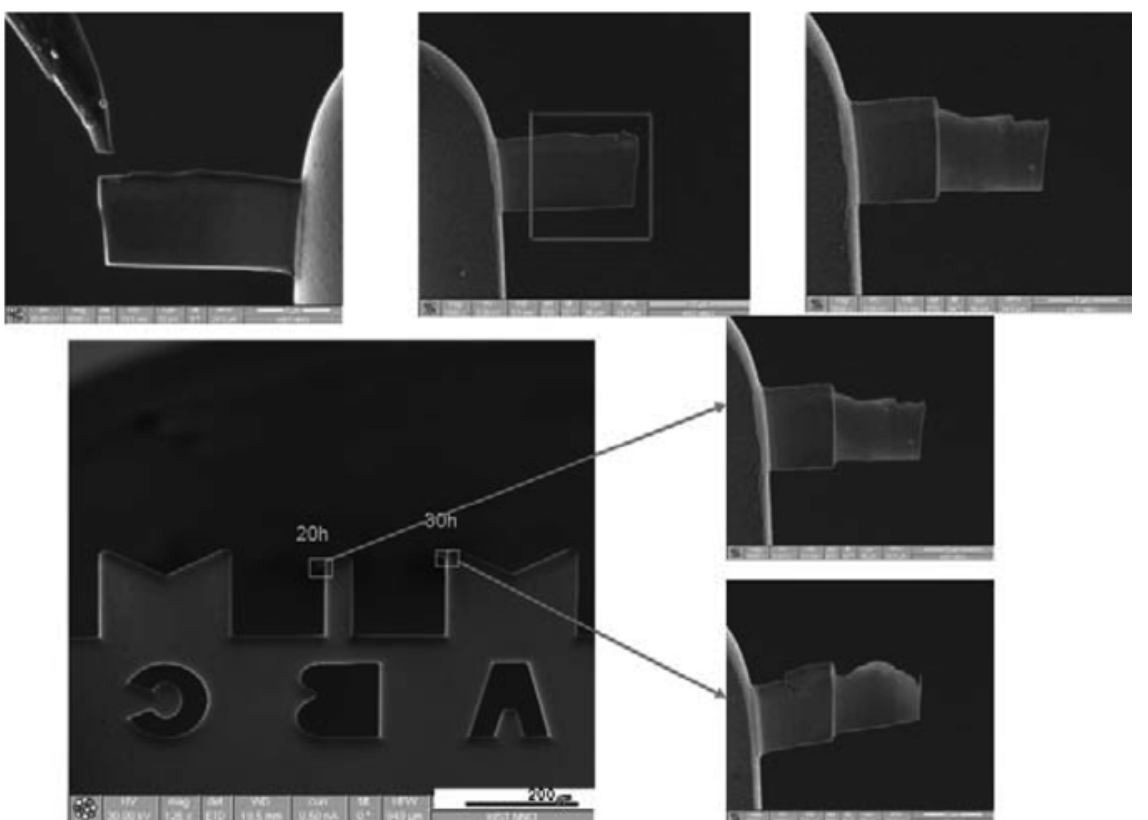

Fig. 1. Preparation of TEM samples using FIB technique.

sured by a K-type thermocouple set on the edge side of the WC die cylinder. Sintering chamber was vacuumed $\left(10^{-3} \mathrm{~atm}\right)$. All parameters were monitored and recorded during the experiment with a heating rate of $100 \mathrm{~K}$ per minute, and the holding time was 3 minutes. SPS temperatures were $663 \mathrm{~K}, 713 \mathrm{~K}, 723 \mathrm{~K}$ and $733 \mathrm{~K}$ to know the formation of crystallization during sintering. The phase changes and densification for all SPS samples were analyzed by the XRD, FE-SEM and OM. 


\section{Results and Discussion}

Morphology, size and microstructures of the asmilled $\mathrm{Ti}_{30} \mathrm{Cu}_{30} \mathrm{Ni}_{20}$ and $\mathrm{Ti}_{50} \mathrm{Cu}_{25} \mathrm{Ni}_{25}$ powders produced at different milling times were observed by FE-SEM and OM as presented in Fig. 2 and Fig. 3. The morphology evolution is changed as the result of the following processes: micro-forging, fracture, agglomeration and de-agglomeration and final steadstate. At the beginning of the ball milling, due to the collision of balls, Ti-Cu-Ni raw powders were deformed and welded together to form large layered powders reaching a maximum average diameter of about 50 $\mu \mathrm{m}$ after 10 hrs of MA (Fig. 2a, b, c, Fig. 3a, b, e, f). In this stage, we could observe the typical lamellar structure. Upon further milling the fracturing process dominated leading the formation of finer powders. After $25 \mathrm{hrs}$ of MA, the powders were substantially decreased in diameter to about $20 \mu \mathrm{m}$ and tend to have nearly spherical-like morphology as seen in Fig. 2d, e and Fig. 3c, g. For a longer milling time above $25 \mathrm{hrs}$, the large sphere particulates were undergone to fine spherical powder because of the fracturing process of MA (Fig. 2f, Fig. 3d, h)). The powders showed uniform particle size distribution within a range from 5 to $20 \mu \mathrm{m}$. The particle sizes at $35 \mathrm{hrs}$ (Fig. $2 \mathrm{~g}$ ) are slightly larger than those at 20 and $30 \mathrm{hrs}$. This can be explained by the mechanical induced softness of the MA powders with increasing milling times.
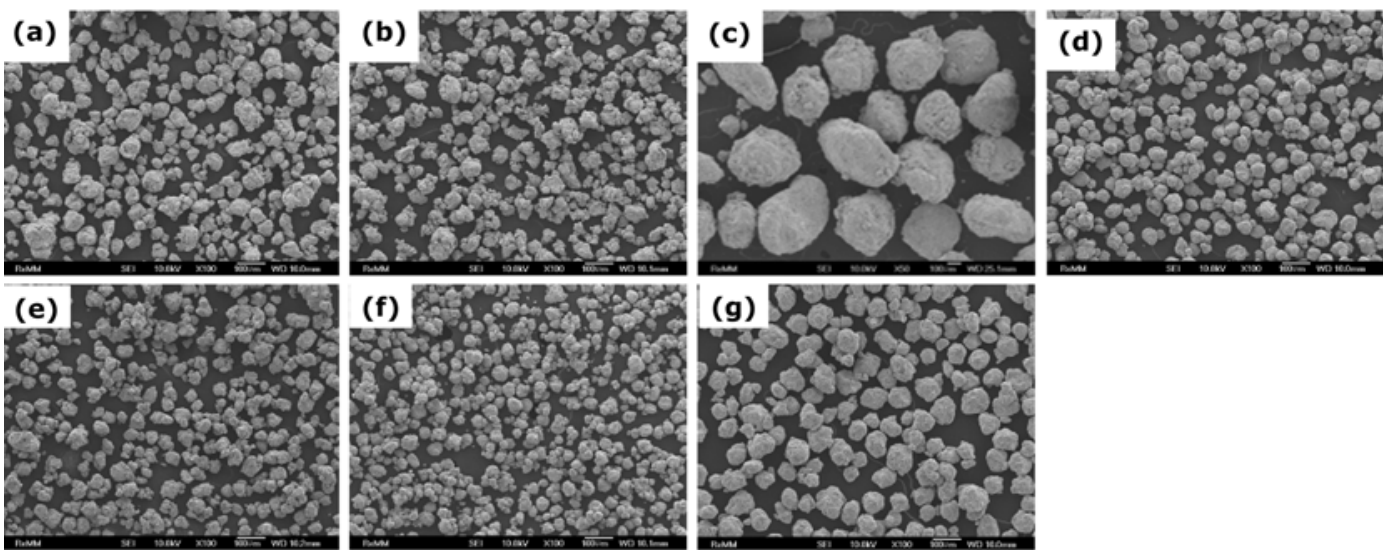

Fig. 2. FE-SEM image of $\mathrm{Ti}_{50} \mathrm{Cu}_{25} \mathrm{Ni}_{25}$ powder with milling times. (a) $2 \mathrm{hrs,} \mathrm{(b)} 5 \mathrm{hrs}$, (c) $10 \mathrm{hrs,} \mathrm{(d)} 20 \mathrm{hrs,} \mathrm{(d)} 25 \mathrm{hrs,} \mathrm{(f)} 30$ hrs and (g) 35 hrs
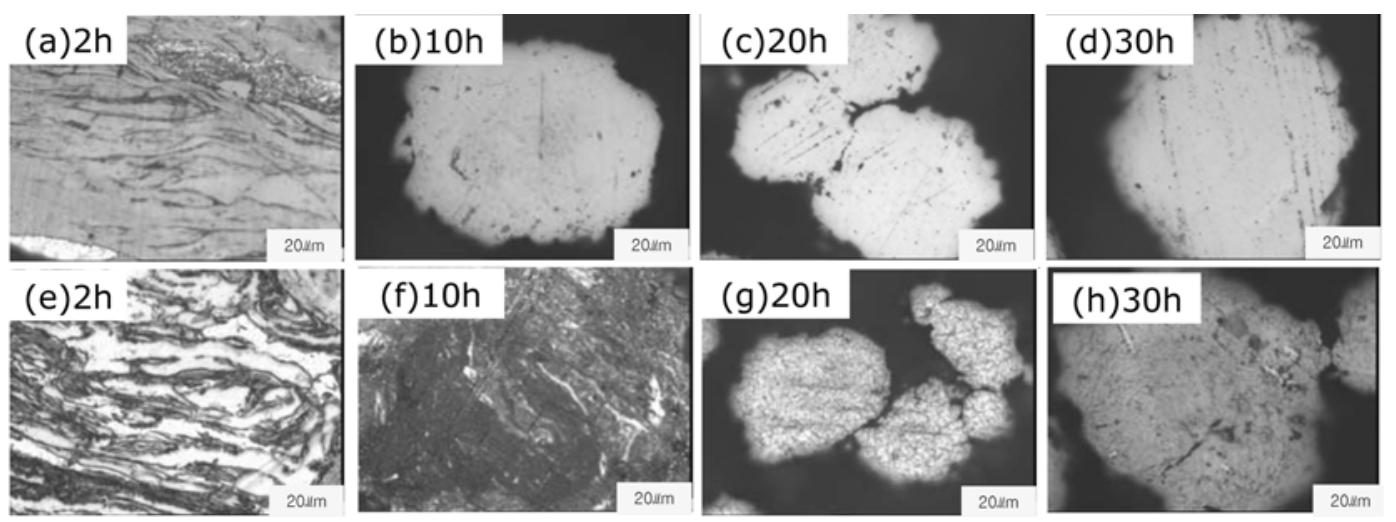

Fig. 3. Optical micrographs of of $\mathrm{Ti}_{50} \mathrm{Cu}_{25} \mathrm{Ni}_{25}$ and $\mathrm{Ti}_{50} \mathrm{Cu}_{30} \mathrm{Ni}_{20}$ powder (a), (e) The microstructure of particle appears lamella structure. (a $\sim \mathrm{d}) \mathrm{Ti}_{50} \mathrm{Cu}_{25} \mathrm{Ni}_{25}$, (e h)Ti $\mathrm{T}_{50} \mathrm{Cu}_{30} \mathrm{Ni}_{20}$, (d), (g). Layer structure was not found. 


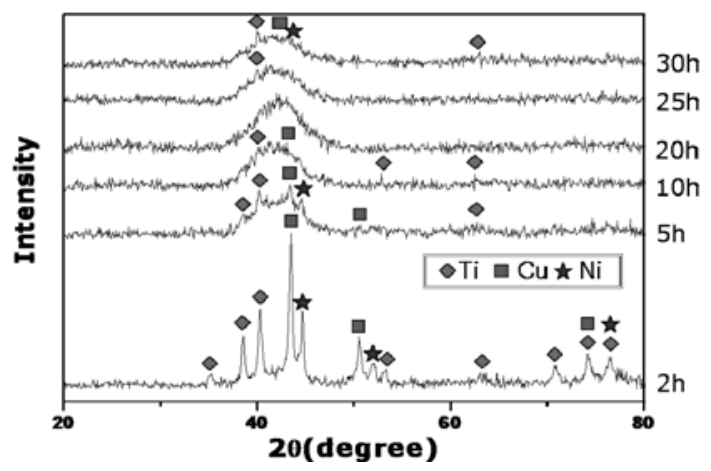

Fig. 4. XRD patterns of $\mathrm{Ti}_{50} \mathrm{Cu}_{30} \mathrm{Ni}_{20}$ milled for (a) $2 \mathrm{hrs,} \mathrm{(b)}$ $5 \mathrm{hrs}$, (c) $10 \mathrm{hrs}$, (d) $20 \mathrm{hrs,} \mathrm{(e)} 25 \mathrm{hrs}$ and (f) $30 \mathrm{hrs}$

$\mathrm{XRD}$ analysis is a conventional technique for understanding the progress of amorphization. Fig. 4 shows the XRD patterns of $\mathrm{Ti}_{50} \mathrm{Cu}_{30} \mathrm{Ni}_{20}$ powders as a function of milling times. After 2 hrs of milling the main peaks of pure $\mathrm{Ti}, \mathrm{Cu}$ and $\mathrm{Ni}$ phases could be found in the XRD patterns. After milling for $10 \mathrm{hrs}$, the elementals' peaks were dramatically disappeared and a broad halo peak corresponding to the amorphous phase was appeared. With increasing milling time, the broadening of diffraction peaks was occurred to be a steady state. At a stage from 5 to 20 hour of milling, the position of diffuse diffraction was saturated at round $35^{\circ}<2 \theta<48^{\circ}$. It indicates that this milling process leads to an enhancement of the chemical homogeneity in the mechanically alloyed amorphous phase until a steady state of the structural evolution approached and a fully amorphous structure is formed. However, in the XRD, $\mathrm{Ti}_{50} \mathrm{Cu}_{30} \mathrm{Ni}_{20}$ showed the mechanical induced-recrystallization at $25 \mathrm{~h}$ at $35 \mathrm{~h}$, respectively. A full amorphous structure can be obtained after 20 hours of milling for $\mathrm{Ti}_{50} \mathrm{Cu}_{30} \mathrm{Ni}_{20}$ alloy. In this study, no intermetallic phases were detected in the amorphous matrix.

Fig. 5. illustrates the DSC scans for the amorphous $\mathrm{Ti}_{50} \mathrm{Cu}_{30} \mathrm{Ni}_{20}$ and $\mathrm{Ti}_{50} \mathrm{Cu}_{25} \mathrm{Ni}_{25}$ alloy samples after $20 \mathrm{~h}$ of MA. The DSC curves exhibit an endothermic event characteristic of the glass transition, followed by a super-cooled liquid region (SLR) $\Delta \mathrm{T}_{\mathrm{x}}=\mathrm{T}_{\mathrm{x}}-\mathrm{T}_{\mathrm{g}}$ and a peak due to primary crystallization. The glass transition temperature, $\mathrm{T}_{\mathrm{g}}$, the onset temperature of
Table 3. Atomic radii, atomic radii mismatch (in \%) and enthalpies of mixing (in $\mathrm{kJ} / \mathrm{mole}$ ) for $\mathrm{Ti}-\mathrm{Cu}-\mathrm{Ni}$ systems

\begin{tabular}{cccc}
\hline \hline Elements & $\mathrm{Ti}$ & $\mathrm{Cu}$ & $\mathrm{Ni}$ \\
\hline $\mathrm{Ti}$ & - & $12.5 \%$ & $14.75 \%$ \\
$\mathrm{Cu}$ & $-11.6 \mathrm{~kJ} /$ mole & - & $2.51 \%$ \\
$\mathrm{Ni}$ & $-38.0 \mathrm{~kJ} /$ mole & $2.9 \mathrm{~kJ} /$ mole & - \\
Atomic radius(nm) & 0.14615 & 0.12780 & 0.12459 \\
\hline
\end{tabular}

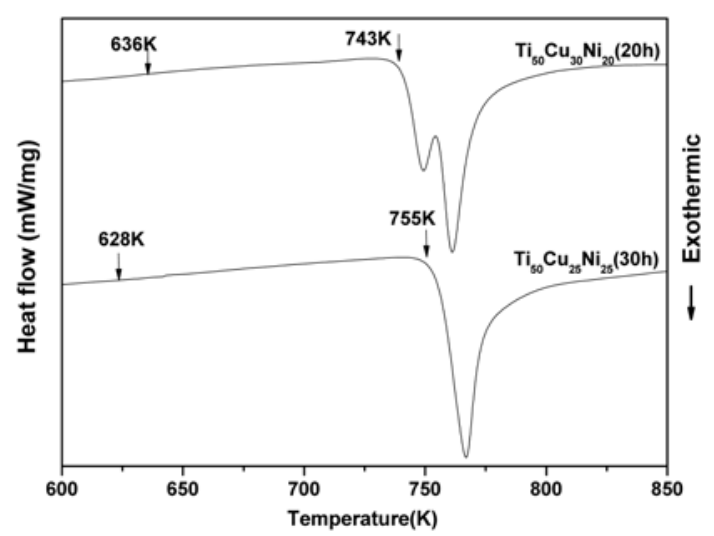

Fig. 5. DSC scans of $20 \mathrm{~h} M A$ (a) $\mathrm{Ti}_{50} \mathrm{Cu}_{30} \mathrm{Ni}_{20}$ and (b) $\mathrm{Ti}_{50} \mathrm{Cu}_{25} \mathrm{Ni}_{25}$.

primary crystallization, $\mathrm{T}_{\mathrm{x}}$ and crystallization enthalpy values for all three alloys are listed in Table 3 . The DSC trace of the $20 \mathrm{hrs}$ milled $\mathrm{Ti}_{50} \mathrm{Cu}_{30} \mathrm{Ni}_{20}$ amorphous alloy was similar to melt-spun sample with the same nominal composition. It was reported that the first sharp exothermic event is related to co-precipitation of $\mathrm{Ti}-(\mathrm{Ni}, \mathrm{Cu})$ and $\mathrm{TiNi}_{2}$ phases from the amorphous phase and the second peak corresponds to crystallization of the residual amorphous phase, leading to a phase mixture of $\mathrm{TiNi}$ and $\mathrm{TiCu}$ after heating [12]. The thermal stability data of $20 \mathrm{hrs}$ mechanically alloyed $\mathrm{Ti}_{50} \mathrm{Cu}_{30} \mathrm{Ni}_{20}$, and $\mathrm{Ti}_{50} \mathrm{Cu}_{25} \mathrm{Ni}_{25}$ samples are slightly different. This may be related to difference in the $\mathrm{Ni}$ content in Ti-Cu-Ni system. Each DSC curve exhibits an incubation period followed by exothermic peaks which corresponds to the crystallization of the metallic glass. It can be seen that the $\Delta \mathrm{T}$ increases with increasing $\mathrm{Ni}$ content because of the large mixing enthalpy of $\mathrm{Ni}$ element compare to $\mathrm{Cu}$ element. Depending on the DSC results we can choose suitable sintering conditions 
Table 4. Crystallization temperatures $\left(T_{x 1}, T_{p 1}\right)$, the glass transition temperature $\left(\mathrm{T}_{\mathrm{g}}\right)$, supercooled liquid region $(\Delta T)$ for $\mathrm{Ti}_{50} \mathrm{Cu}_{30} \mathrm{Ni}_{20}$ and $\mathrm{Ti}_{50} \mathrm{Cu}_{25} \mathrm{Ni}_{25}$ alloys

\begin{tabular}{cccccc}
\hline \hline Composition & $\mathrm{T}_{\mathrm{g}}(\mathrm{K})$ & $\mathrm{Tx}_{1}(\mathrm{~K})$ & $\mathrm{T}_{\mathrm{p} 1}(\mathrm{~K})$ & $\Delta \mathrm{T}(\mathrm{K})$ & $\Delta \mathrm{H}(\mathrm{J} / \mathrm{g})$ \\
\hline $\mathrm{Ti}_{50} \mathrm{Cu}_{30} \mathrm{Ni}_{20}$ & 636 & 743 & 761 & 107 & 86.3 \\
$\mathrm{Ti}_{50} \mathrm{Cu}_{25} \mathrm{Ni}_{25}$ & 628 & 755 & 767 & 139 & 69.9 \\
\hline
\end{tabular}

for consolidating of the MA Ti-Cu-Ni powders.

The high-resolution transmission electron micrograph (HR-TEM) and the corresponding electron diffraction pattern of the $\mathrm{Ti}_{50} \mathrm{Cu}_{25} \mathrm{Ni}_{25}$ powder after milling for $25 \mathrm{hrs}$ are given in Fig. 6. A selected area diffraction pattern (SADP) taken from this region shows a diffuse halo ring, indicating the amorphous structure of the alloy. Also the lattice images of HRTEM clearly show that all atoms of the MA powders were randomly oriented. No grain boundaries and pores were existed in the images. However, in the high magnified HR-TEM images, we can detect the very small nanocrystailline with size of 1-2 nm, i.e., short range ordered structured crystalline composed of 5-10 atoms (indicated by circles). These short ranged ordered structures could not be analyzed by XRD results, but using FIB technique, these could be clearly revealed in the HR-TEM.

After preparing full amorphous $\mathrm{Ti}_{50} \mathrm{Cu}_{25} \mathrm{Ni}_{25}$ powder using MA process, the bulk samples were produced by spark plasma sintering. The sintering conditions of the each alloy were chosen based on their DSC results. FE-SEM of $\mathrm{Ti}_{50} \mathrm{Cu}_{25} \mathrm{Ni}_{25}$ samples sintered at $663 \mathrm{~K}$ (Fig. 7a) shows lots of pores in the samples. Even the sintering temperature, $663 \mathrm{~K}$, was in the range of SCL of DSC results (Table 4), it was not enough to get the full densification. The relative density value of this sample was only $76 \%$. The amorphous phase of the as-prepared powders was maintained in this temperature even though the spark plasma sintering was applied. But, at $723 \mathrm{~K}$, the SPS sample showed all most full density, 98.5\%. At higher sintering temperature higher relative den-
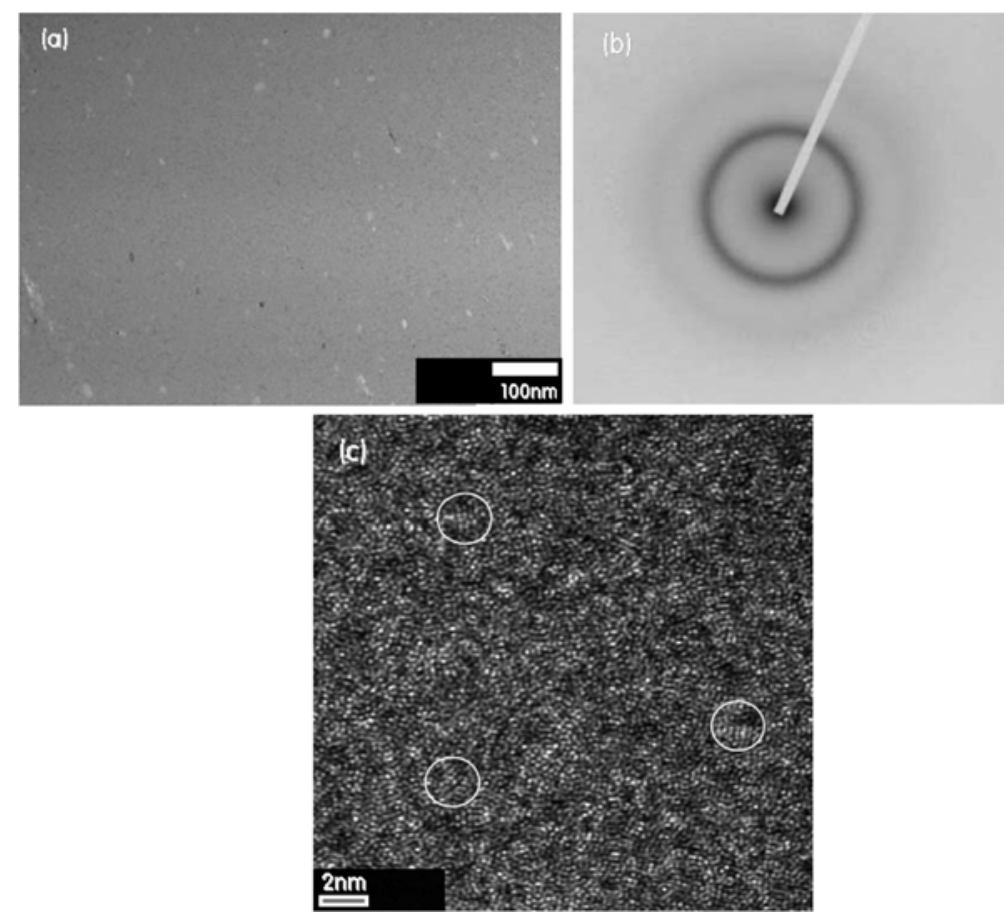

Fig. 6. HR-TEM results of MA amorphous TiCuNi powder. (a) low magnified image, (b) SAD pattern and (c) high magnified lattice image 

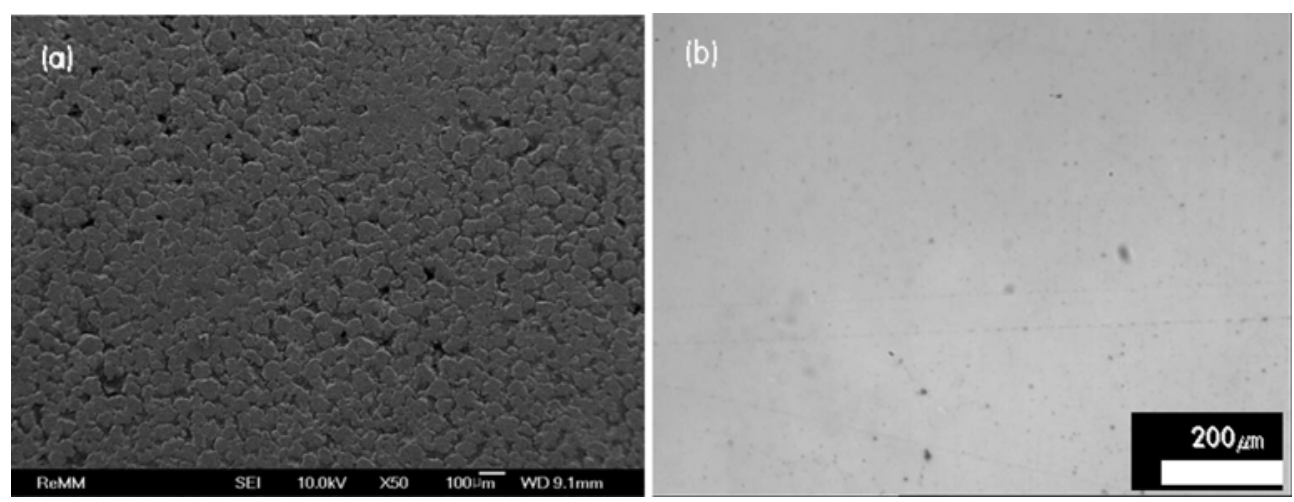

Fig. 7. FE-SEM and $O M$ of SPS $\mathrm{Ti}_{50} \mathrm{Cu}_{25} \mathrm{Ni}_{25}$ samples. (a) $663 \mathrm{~K}$ and (b) $723 \mathrm{~K}$

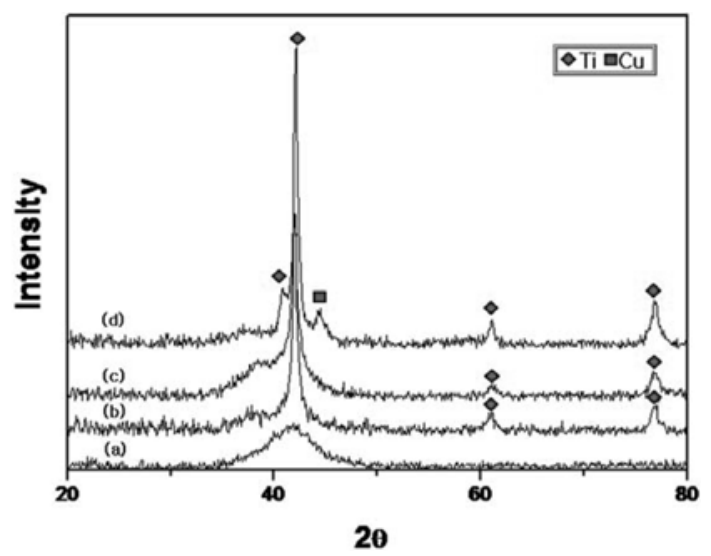

Fig. 8. XRD results of SPS $\mathrm{Ti}_{50} \mathrm{Cu}_{25} \mathrm{Ni}_{25}$ samples. (a) $663 \mathrm{~K}$, (b) $713 \mathrm{~K}$, (c) $723 \mathrm{~K}$ and (d) $733 \mathrm{~K}$

sity could be obtained. However, when the temperature of the spark plasma sintering process was passed over $713 \mathrm{~K}$, the samples were partially crystallized after sintering because of partial over heating during SPS process. Peaks belong to Ti phase could be immediately detected in the XRD patterns showing in Fig. 8. At $733 \mathrm{~K}$, the pure $\mathrm{Cu}$ peak also appeared together with Ti peaks.

\section{Conclusions}

A fully amorphous structure could be successfully obtained after 20 hour, 25 hour of mechanical alloying process for $\mathrm{Ti}_{50} \mathrm{Cu}_{30} \mathrm{Ni}_{20}$ and $\mathrm{Ti}_{50} \mathrm{Cu}_{25} \mathrm{Ni}_{25}$. The $\mathrm{Ti}_{50} \mathrm{Cu}_{25} \mathrm{Ni}_{25}$ alloy showed the better glass forming ability (GFA) and thermal stability. With increasing the Ni contents, the GFA was increased because of the large mixing enthalpy of Ni element. By using FIB technique, nano-crystallites in size of 1-2 nm were found in the amorphous matrix by HR-TEM. The full densified TiCuNi amorphous bulk sample could be successfully produced by the spark plasma sintering process. At higher sintering temperature higher relative density could be obtained. The relative density of the SPS sample processed at $723 \mathrm{~K}$ was about $98.5 \%$. However, crystallization of $\mathrm{Ti}$ and $\mathrm{Cu}$ elements during spark plasma sintering was happened at $733 \mathrm{~K}$.

\section{Acknowledgements}

This work was supported by the 2007 Research Fund of the University of Ulsan.

\section{References}

[1] A. Inoue: Metal. Nater. Internat., 48 (2000) 279.

[2] W. B. Kim, B. J. Ye and S. Yi: Mater. Sci. Eng. A, 1 (2004) 1.

[3] Y. J. Liu and I. T. H. Chang: Mater. Sci. Eng. A, 325 (2002) 25.

[4] Z. Fuqian, X. Ming, L. Jianliang, L. Xianyong, G. Weiming, S. An and D. Zhongmin: Mater. Sci. Eng. A, 304-306 (2001) 579 .

[5] S. D. De la Torre, D. Oleszak, A. Kakitsuji, K. Miyamoto, H. Miyamoto, R. Martinez-S., F. Almeraya-C, A. Martinez-V. and D. Rios-J: Materials Science and Engineering A, 276 (2000) 226. 
[6] T. Zhang, A. Inoue and T. Masumoto: Mater. Sci. Eng. A, 181/182 (1994) 1423.

[7] A. Inoue, N. Nishiyama and T. Masumoto: Mater. Lett., 19 (1994) 131.

[8] K. Amiya, N. Nishiyama, A. Inoue and T. Masumoto: Mater. Sci. Eng. A, 179/180 (1994) 692.

[9] T. Zhang and A. Inoue: Mater. Trans. JIM, 39 (1998)
1001

[10] P. P. Choi, Y. S. Kwon, J. S. Kim and T. Al-Kassab: J. Electron Microscopy, 56 (2007) 43.

[11] L. A. Giannuzzi, J. L. Drown, S. R. Brown, R. B. Irwin and F. A. Stevie: Microsc. Res. Tech., 41 (1998) 285.

[12] D. V. Louzguine and A. Inoue: Scripta Mater., 43 (2000) 371. 